This is a self-archived version of an original article. This version may differ from the original in pagination and typographic details.

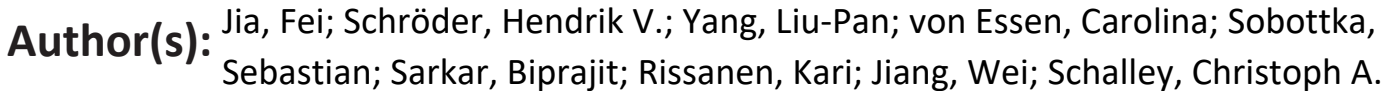

Title: Redox-Responsive Host-Guest Chemistry of a Flexible Cage with Naphthalene Walls

Year: 2020

Version: Accepted version (Final draft)

Copyright: @ 2020 American Chemical Society

Rights: In Copyright

Rights url: http://rightsstatements.org/page/InC/1.0/?language=en

Please cite the original version:

Jia, F., Schröder, H. V., Yang, L.-P., von Essen, C., Sobottka, S., Sarkar, B., Rissanen, K., Jiang, W., \& Schalley, C. A. (2020). Redox-Responsive Host-Guest Chemistry of a Flexible Cage with Naphthalene Walls. Journal of the American Chemical Society, 142(7), 3306-3310. https://doi.org/10.1021/jacs.9b11685 
Subscriber access provided by JYVASKYLAN UNIV

Communication

\section{Redox-Responsive Host-Guest Chemistry of a Flexible Cage with Naphthalene Walls}

Fei Jia, Hendrik V. Schröder, Liu-Pan Yang, Carolina von Essen, Sebastian Sobottka, Biprajit Sarkar, Kari Rissanen, Wei Jiang, and Christoph A. Schalley

J. Am. Chem. Soc., Just Accepted Manuscript • Publication Date (Web): 04 Feb 2020

Downloaded from pubs.acs.org on February 5, 2020

\section{Just Accepted}

"Just Accepted" manuscripts have been peer-reviewed and accepted for publication. They are posted online prior to technical editing, formatting for publication and author proofing. The American Chemical Society provides "Just Accepted" as a service to the research community to expedite the dissemination of scientific material as soon as possible after acceptance. "Just Accepted" manuscripts appear in full in PDF format accompanied by an HTML abstract. "Just Accepted" manuscripts have been fully peer reviewed, but should not be considered the official version of record. They are citable by the Digital Object Identifier (DOI®). "Just Accepted" is an optional service offered to authors. Therefore, the "Just Accepted" Web site may not include all articles that will be published in the journal. After a manuscript is technically edited and formatted, it will be removed from the "Just Accepted" Web site and published as an ASAP article. Note that technical editing may introduce minor changes to the manuscript text and/or graphics which could affect content, and all legal disclaimers and ethical guidelines that apply to the journal pertain. ACS cannot be held responsible for errors or consequences arising from the use of information contained in these "Just Accepted" manuscripts. 
In nature, flexible dynamic systems like proteins, fold to achieve sophisticated biological function. ${ }^{1}$ For example, enzymes rely on adaptive conformational changes (induced fit) ${ }^{2}$ to strongly and selectively bind substrates in their active pockets. ${ }^{3}$ Flat aromatic DNA intercalators insert between base pairs through a dynamic local deformation of the DNA double helix. ${ }^{4}$ Conversely, the design of synthetic receptors relied mainly on the development of preorganized rigid structures to improve binding strength and selectivity. However, this preorganization comes with the drawbacks of reduced flexibility and adaptability. As an example, Stoddart's rigid cyclobis(paraquat- $p$-phenylene) macrocycle ${ }^{5}$ $\left(\mathrm{CBPQT}^{4+}\right.$, the "blue box") is frequently used for the complexation with planar electron-rich molecules to construct mechanically interlocked molecules. Such rigid structures cannot easily undergo conformational changes to respond to environmental changes. Rigid redox-responsive host-guest complexes have been extensively studied ${ }^{6}$ aiming at stimuliresponsive supramolecular materials, whose properties can be mediated by redox-induced changes in charge and electron distribution. Conformationally flexible hosts, in contrast, can respond to different shapes of guests as well as environmental stimuli.

Recently, we developed a series of naphthol-based ${ }^{7}$ receptors including the so-called "naphthocage" (NC, Figure 1). NC is highly flexible as expressed in the self-inclusion conformation of

the free cage, in which one of the naphthalene walls is intercalated between the other two. Its flexibility is also expressed in the fast naphthalene ring flips that interconvert the self-inclusion conformers a)

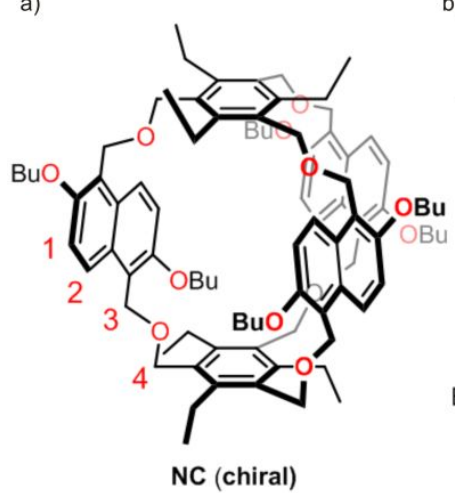

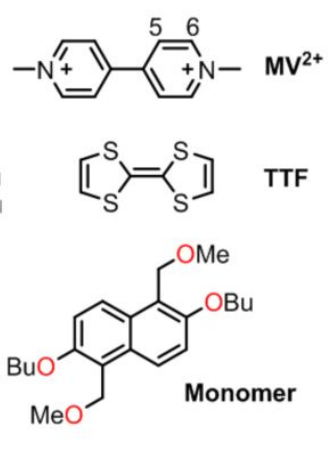

Figure 1. Chemical structures of (a) naphthocage (NC) and (b) methyl viologen $\left(\mathbf{M V}^{2+}\right.$, the counterions are $\left.\mathrm{PF}_{6}^{-}\right)$, tetrathiafulvalene (TTF) and control compound Monomer. NC is chiral (only one enantiomer is shown here). Numbering on the structures corresponds to the assignments of the NMR signals in Figure 3.

with two host conformers of $D_{3}$ (NC-I) and $C_{2}$ symmetry (NCII). ${ }^{8}$ Despite this remarkable flexibility, NC exhibits strong binding affinities up to $10^{9} \mathrm{M}^{-1}$ to organic cations such as $\mathrm{Me}_{4} \mathrm{~N}^{+}$, ferrocenium $\left(\mathbf{F c}^{+}\right)$or acetylcholine. An astonishingly high binding selectivity $\left(\sim 10^{15}\right)$ was observed for $\mathbf{F c}^{+}$over ferrocene $\mathbf{F c}$.

Here, we investigate the binding of NC to aromatic dications (Figure 1b) of tetrathiafulvalene and methyl viologen - two of the most widely used redox-switchable building blocks in supramolecular chemistry. ${ }^{9}$ These dications, whose shapes do not exactly match that of the cage's cavity, intercalate between two naphthalene walls with unexpected binding strength. Not only the guests are redox-responsive resulting in switchable host-guest complexes, but also the host can be reversibly oxidized to control guest release. 
For the complex of $\mathbf{N C}$ with electron-poor $\mathbf{M V}^{2+}$, a single crystal structure was obtained (Figure 2). $\mathbf{M V}^{2+}$ is intercalated into the cage cavity (Figure $\mathrm{S} 1$ ). Both enantiomers of the $C_{l}$ symmetric complex are incorporated in the crystal (Figures S2-S3). The dihedral angle along the bond connecting the two pyridinium rings is $33.8^{\circ}$. The two naphthalene walls flanking the guest do not perfectly parallel the inner pyridinium ring of the guest. This results
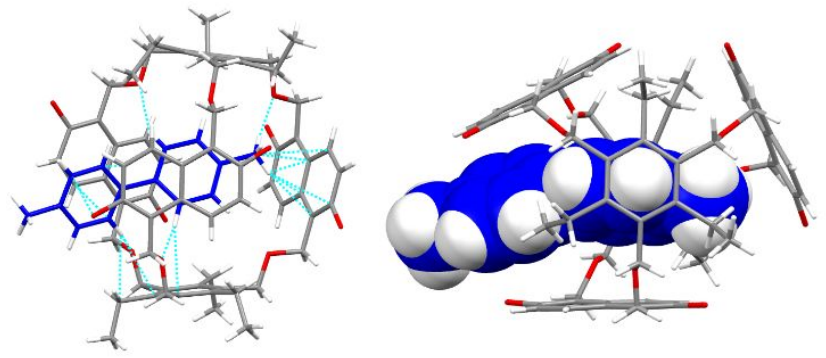

Figure 2. Single crystal structure of $\mathbf{M V}^{2+} @ \mathbf{N C}$. Butyl groups and $\mathrm{PF}_{6}$ counterions are removed for viewing clarity. The $\mathbf{M V}^{2+}$ is colored in blue.

in a slight bending of the guest. Charge transfer interactions contribute to the binding, as indicated by the charge transfer band observed in the UV/Vis spectrum of the complex and its reddish color (Figure S4). In addition, close contacts (Figure 2, left) suggest multiple $\mathrm{C}-\mathrm{H} \cdots \mathrm{O}, \mathrm{C}-\mathrm{H} \cdots \pi$, and cation $\cdots \pi$ interactions are important for complex formation. The 1:1 host-guest stoichiometry in solution is confirmed by ESI mass spectrometry (Figure S5). Isothermal titration calorimetry resulted in a binding constant of $2 \times 10^{7} \mathrm{M}^{-1}$ in 1,2-dichloroethane/acetonitrile (1:1) (Figures S8-S10). Additionally, the new guests trimethylsulfonium (TMS $^{+} ; K_{a}=1.8 \times 10^{7} \mathrm{M}^{-1}$ ) and tetramethylphosphonium (TMP+; $K_{a}=5.1 \times 10^{7} \mathbf{M}^{-1}$ ) reveal strong binding as well (Figures S11-S12).

c)

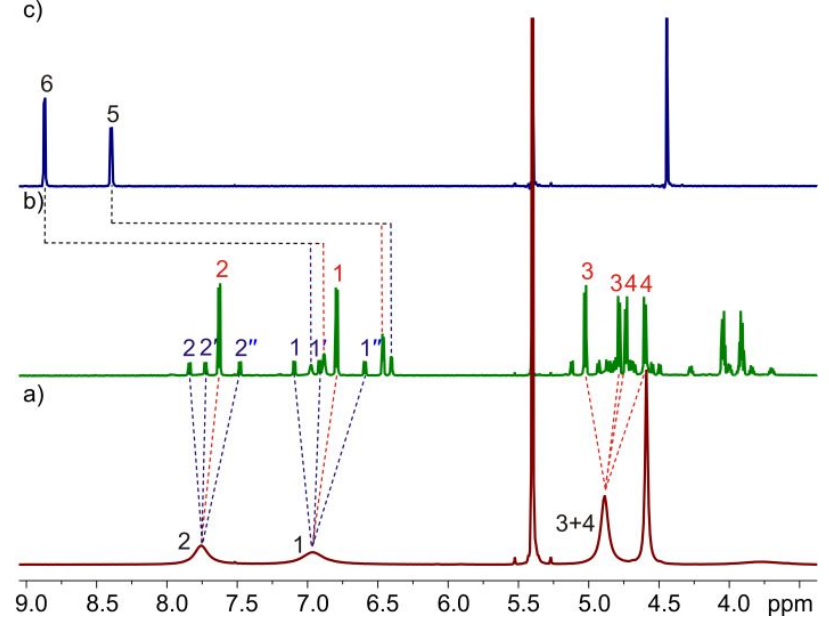

Figure 3. Partial ${ }^{1} \mathrm{H}$ NMR spectra $\left(700 \mathrm{MHz}, 2.0 \mathrm{mM}, \mathrm{CD}_{2} \mathrm{Cl}_{2}\right.$ : $\mathrm{CD}_{3} \mathrm{CN}=1: 1,298 \mathrm{~K}$ ) of (a) $\mathbf{N C}$, (b) $\mathbf{M V}^{2+} @ \mathbf{N C}$, and (c) $\mathbf{M V}^{2+}$.

Typical upfield shifts of ca. 2 ppm of guest signals 5 and 6 in the ${ }^{1} \mathrm{H}$ NMR spectrum of the complex (Figures 3 and S13) evidence binding of the dication inside the cavity. This is supported by cross peaks between host and guest signals in the 2D ROESY spectra (Figures S14 and S15). The broad signals for protons 1 and 2 of the free host sharpen upon complex formation. Two sets of signals are observed: two more intense doublets (red labels, Figure 3) can be assigned to the complex of conformer NC-I (67\%), the six smaller doublets (blue labels) to the complex with
NC-II (33\%). Also, two sets of signals are observed for the guest protons 5 and 6 integrating in a $67: 33$ ratio. The observation of separate sets of signals for both complex conformers confirms guest exchange to be slow on the NMR time scale. ${ }^{1} \mathrm{H},{ }^{1} \mathrm{H}$ EXSY experiments (Figures S20-S24) with $\mathbf{M V}^{\mathbf{2}} @ \mathbf{N C}$ reveal two sets of off-diagonal cross peaks that translate into exchange rates of $k_{\mathrm{I}}$ $=0.66 \mathrm{~s}^{-1}\left(t_{1 / 2}=1.05 \mathrm{~s}\right)$ and $k_{\mathrm{II}}=1.19 \mathrm{~s}^{-1}\left(\mathrm{t}_{1 / 2}=0.58 \mathrm{~s}\right)$ for $\mathbf{M V}^{2+} @ \mathbf{N C}-\mathbf{I}$ and $\mathbf{M V}^{2+} @ \mathbf{N C}-\mathbf{I I}$, respectively (Figures S25-S26). ${ }^{10}$ From the $C_{1}$ symmetry of the complex in the crystal, one would have expected a more complicated NMR spectrum. Consequently, we can conclude that the guest must be mobile within the cavity being able to shift back and forth quickly between the three cage portals. On time average, this dynamic process results in sets of signals as expected for the $D_{3}$ (NC-I) and $C_{2}$ (NC-II) symmetric conformers. At the same time, it rationalizes, why only one set of guest protons appears for the guest in each of the two complexes. This behavior is reminiscent of Huc's helical foldamer complexes, in which guest shuttling inside the helix is much faster than disand reassembly of the complex. ${ }^{11}$

Reduction of the guest in $\mathbf{M V}^{\mathbf{2}} @ \mathbf{N C}$ to the corresponding radical cation $\mathbf{M V}^{\bullet+}$ and neutral $\mathbf{M V}$ significantly differs from that of free $\mathbf{M V}^{2+}{ }^{12}$ Addition of 1 equiv. NC cathodically shifts the first reduction potential (Figure S27), while the second one broadens (Figure S28) indicating the reduction to occur inside the cage. At higher scan rates $\left(1-20 \mathrm{~V} \cdot \mathrm{s}^{-1}\right)$, the cyclic voltammograms $(\mathrm{CVs})$ reveal significant new signals, which correspond to the $\mathbf{M V}^{\bullet+} / \mathbf{M V}$ reduction inside NC (Figure S29). Digital simulations based on a six-membered square scheme provide thermodynamic and kinetic parameters (Figure S30, Table 1). The dissociation rate obtained for $\mathbf{M V}^{2+} @ \mathbf{N C}$ is well comparable to the EXSY data. The simulations also reveal the radical cation $\mathbf{M V}^{\bullet+}$ to be a reasonable guest for NC. Furthermore, neutral MV leaves the cage with quite a high dissociation rate. Reduction of $\mathbf{M V}^{\mathbf{2}}$ to its neutral counterpart thus allows switching between the host-guest complex and the empty host and thus controls guest release.

Table 1. Thermodynamic and kinetic parameters obtained by digital simulations of the cyclic voltgammograms. ${ }^{a, b}$

\begin{tabular}{ccccc}
\hline Guest & $\begin{array}{c}\text { Oxidation } \\
\text { state }\end{array}$ & $\begin{array}{c}\boldsymbol{K}_{\mathbf{a}} \\
\left(\mathbf{M}^{-1}\right)\end{array}$ & $\begin{array}{c}\boldsymbol{k}_{\mathbf{f}} \\
\left(\mathbf{M}^{-1} \cdot \mathbf{s}^{-1}\right)\end{array}$ & $\begin{array}{c}\boldsymbol{k}_{\mathbf{b}} \\
\left(\mathbf{s}^{-1}\right)\end{array}$ \\
\hline $\mathbf{M V}$ & 0 & $1.5 \times 10^{-3}$ & 2.0 & $1.4 \times 10^{3}$ \\
$\mathbf{M V}^{+}$ & $1+$ & $5.7 \times 10^{3}$ & $1.0 \times 10^{7}$ & $1.8 \times 10^{3}$ \\
$\mathbf{M V}^{2+}$ & $2+$ & $(2.0 \pm 0.2) \times 10^{7 c}$ & $2.0 \times 10^{7}$ & 1.0 \\
$\mathbf{T T F}$ & 0 & $5.8 \times 10^{-3}$ & $/ d$ & $/ d$ \\
$\mathbf{T T F}^{++}$ & $1+$ & $1.6 \times 10^{8}$ & $8.8 \times 10^{7}$ & 0.5 \\
$\mathbf{T T F}^{2+}$ & $2+$ & $3.1 \times 10^{10}$ & $1.9 \times 10^{8}$ & $6.1 \times 10^{-3}$ \\
\hline
\end{tabular}

${ }^{a} \mathrm{CVs}$ measured in 1,2-dichloroethane/acetonitrile $(1: 1)$ at $298 \mathrm{~K}$ with $n-\mathrm{Bu}_{4} \mathrm{NPF}_{6}$ electrolyte $(0.1 \mathrm{M}) .{ }^{b}$ for evaluation of the accuracy of the simulations see Figure S35. ${ }^{c}$ from isothermal titration calorimetry. ${ }^{d}$ Simulations did not provide reliable rate constants.

In contrast, TTF can be reversibly oxidized to a stable radical cation $\left(\mathbf{T T F}^{\cdot+}\right)$ and a dication $\left(\mathbf{T T F}^{2+}\right) .{ }^{13}{ }^{1} \mathrm{H}$ NMR spectra show TTF not to be encapsulated inside NC (Figure S31). However, strong binding was observed for $\mathbf{T T F}^{++}$and $\mathbf{T T F}^{2+}$ as demonstrated by CV (Figure 4). Both anodic peak potentials for TTF oxidations cathodically shift after addition of 1 equiv. NC. The most significant effect is observed for the $\mathbf{T T F} / \mathbf{T T F}^{\cdot+}$ cathodic peak potential, which shifts by $-0.5 \mathrm{~V}$ (Figure S32) indicating complex dissociation after reducing $\mathbf{T T F}^{*+}$ to TTF. The second oxidation $\left(\mathbf{T T F}^{++} / \mathbf{T} \mathbf{T F}^{2+}\right.$ ) occurs inside the cage (Figure S33). Digital simulations based on the square scheme in Figure $4 \mathrm{c}$ 
reproduce the experimental $\mathrm{CV}$ traces (Figures $4 \mathrm{~b}, \mathrm{~S} 34$ ) and yields the kinetic and thermodynamic parameters as a set of selfconsistent values (Table 1) showing virtually no binding of TTF, strong binding of $\mathbf{T T F}^{+}$, and extremely strong binding of $\mathbf{T T F}^{2+}$ $\left(3.1 \times 10^{10} \mathbf{M}^{-1}\right)$. A comparison of $\mathbf{T T F}^{2+}$ and $\mathbf{M V}{ }^{2+}$ shows that both guests can be switched in and out by redox-stimuli with quite high binding selectivity factors $\left(10^{10}\right.$ to $\left.10^{12}\right)$.

During these electrochemical studies, we found that the empty cage itself can also be oxidized. The cyclic voltammograms of free NC surprisingly show two signals $(\sim 1: 2$ ratio) for the stepwise oxidations of the three naphthalene rings (Figures $5 \mathrm{a}$ and S39). The first oxidation yields radical cation $\mathbf{N C}^{-+}$, which is stabilized by self-inclusion of the oxidized naphthalene between the other two walls. Two-electron oxidation further leads to $\mathbf{N C}^{3(+)}$ and charge repulsion-driven unfolding of the selfinclusion conformation of the

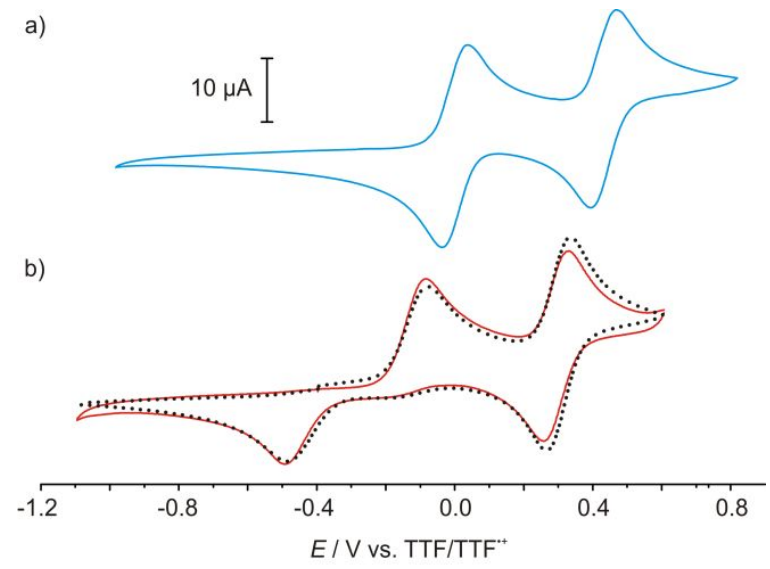

c)

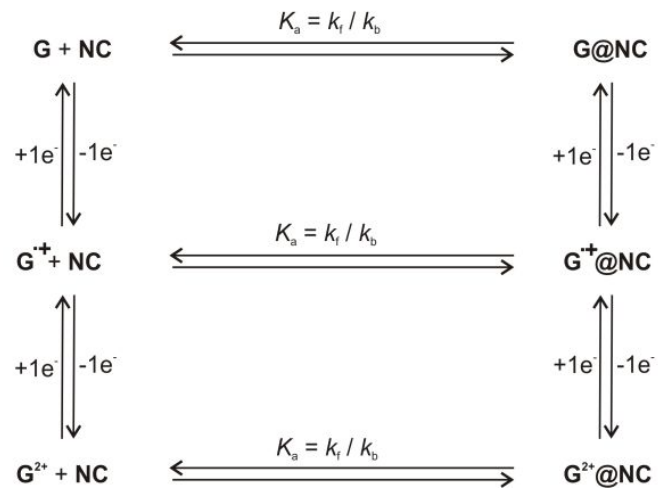

Figure 4. $\mathrm{CVs}$ of TTF $\left(\mathrm{ClCH}_{2} \mathrm{CH}_{2} \mathrm{Cl}: \mathrm{CH}_{3} \mathrm{CN}=1: 1,1.0 \mathrm{mM}\right.$, $\left.298 \mathrm{~K}, 100 \mathrm{mV} \cdot \mathrm{s}^{-1}\right)$ with $n-\mathrm{Bu}_{4} \mathrm{NPF}_{6}$ electrolyte $(0.1 \mathrm{M})$ (a) before and (b) after addition of 1 equiv. NC (dotted line: $\mathrm{CV}$ simulated based on parameters in Table 1). (c) Six-membered square scheme used for digital simulations $(\mathrm{G}=$ guest $)$.

cage. Cyclic voltammograms at different scan rates confirm a reversible first and at least a quasi-reversible second oxidation (Figure S40). The peak potential difference of $0.21 \mathrm{~V}$ corresponds to a radical-cation stabilization energy of $20 \mathrm{~kJ} \cdot \mathrm{mol}^{-1}$ for $\mathbf{N C}^{++}$. The energetically stabilized $\mathbf{N C}^{++}$state is further underpinned by spectroelectrochemistry (SEC). CW-EPR SEC (Figures $5 \mathrm{~b}$ and S41) reveals an isotropic signal at $g=2.003$ upon oxidation of NC. In contrast, CV and CW-EPR experiments of the control Monomer revealed one-electron oxidation at $E_{1 / 2}=0.73 \mathrm{~V}$ vs. $\mathbf{F c} / \mathbf{F c}^{+}$followed by an irreversible chemical reaction along an $\mathrm{EC}_{\mathrm{i}}$ mechanism (Figure S42). Thus, the self-inclusion conformation significantly stabilizes the $\mathbf{N C}^{++}$state and surprisingly allows reversible generation of a stable naphthalene radical cation, as additionally indicated by UV/Vis-NIR spectroelectrochemistry
(Figure S43). Upon addition of 1 equiv. Fe to free NC, the first oxidation wave vanishes as result of occupied cage. Only one broad three-electron oxidation wave is observed (Figure S44). The potential of $\mathbf{F} \mathbf{c}^{+} @ \mathbf{N C}\left(E_{1 / 2}=0.80 \mathrm{~V}\right.$ vs. $\left.\mathrm{Fc} / \mathrm{Fc}^{+}\right)$is $70 \mathrm{mV}$ higher than that of Monomer. This increase is a result of the encapsulated cationic guest.

Starting from the crystal structure of the self-inclusion conformation of free NC, ${ }^{8}$ a spin density plot of $\mathbf{N C}^{-+}$(Figures $5 \mathrm{c}$ and S45) obtained by DFT calculations (COSMO/B3LYP-D3(BJ)) illustrates the radical cation to be mainly delocalized on the naphthalene unit in the cavity. The comparison of calculated oxidation energy differences $\left(\mathbf{N C} / \mathbf{N C}^{++}\right.$and Monomer/Monomer ${ }^{++}$) also indicates an energetically favorable $\mathbf{N C} / \mathbf{N C}^{*+}$ oxidation (Table $\mathrm{S} 1$ ).

The oxidation of NC releases encapsulated guests as demonstrated for $\mathbf{M V}^{2+}$ cobaltocenium $\left(\mathbf{C c}^{+}\right)^{8}$, trimethylsulfonium $\left(\mathbf{T M S}^{+}\right)$, tetrmethylphosphonium $\left(\mathbf{T M P}^{+}\right)$, choline $\left(\mathbf{C h}^{+}\right)$and acetyl choline $\left(\mathbf{A} \mathbf{c h}^{+}\right)$that are among the strongest guests for NC known so far. ${ }^{1} \mathrm{H}$ NMR spectra (Figures S46-S53) indicate chemical oxidation of $\mathbf{M V}^{2+} @ \mathbf{N C}, \mathbf{C c}^{+} @ \mathbf{N C}$, TMS $@ \mathbf{N C}, \mathbf{T M P} \mathbf{P}^{+} @ \mathbf{N C}, \mathbf{C h}^{+} @ \mathbf{N C}$ or $\mathbf{A c h}^{+} @ \mathbf{N C}$ by $\mathrm{NOPF}_{6}$ to result in a (likely full) oxidation of $\mathbf{N C}$ and liberates the encapsulated $\mathbf{M V}^{2+}, \mathbf{C c}^{+}, \mathbf{T M S}^{+}, \mathbf{T M P}^{+}, \mathbf{C h}^{+}$and $\mathbf{A c h}^{+}$, respectively. However, the oxidation to $\mathbf{N C}^{3(+)}$ is a quasireversible process and is potentially followed by a slow decomposition (Figure S40 and S42). Thus, a chemical reduction using reductants such as $\mathrm{Zn}$ or $\mathrm{NaBH}_{4}$, was not successful and the redox-controlled release process appears to be irreversible.

a)

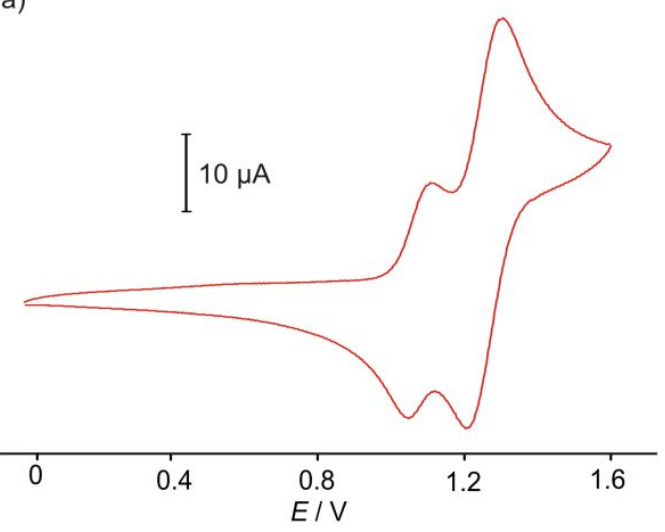

b)

c)
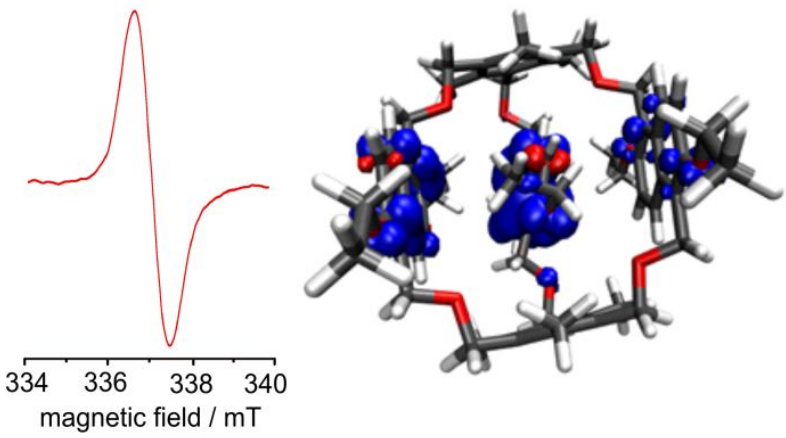

Figure 5. (a) $\mathrm{CV}$ of $\mathrm{NC}\left(\mathrm{ClCH}_{2} \mathrm{CH}_{2} \mathrm{Cl}: \mathrm{CH}_{3} \mathrm{CN}=1: 1,1.0 \mathrm{mM}\right.$, $\left.298 \mathrm{~K}, 100 \mathrm{mV} \cdot \mathrm{s}^{-1}\right)$ with $n-\mathrm{Bu}_{4} \mathrm{NPF}_{6}$ electrolyte $(0.1 \mathrm{M})$. Potential given against a silver wire pseudo-reference electrode. (b) $\mathrm{CW}$ EPR spectroelectrochemistry $\left(\mathrm{CH}_{2} \mathrm{Cl}_{2}: \mathrm{CH}_{3} \mathrm{CN}=1: 1,1.0 \mathrm{mM}\right.$, $298 \mathrm{~K})$ of $\mathrm{NC}$ with $n-\mathrm{Bu}_{4} \mathrm{NPF}_{6}$ electrolyte $(0.1 \mathrm{M})$. (c) Spin density plot of $\mathbf{N C}^{\bullet+}$. Blue/red regions represent positive/negative spin density. 
In summary, we report the extremely strong complexation of the $\mathbf{T T F}^{2+}$ and $\mathbf{M V}^{2+}$ dications inside the "naphthocage" with affinities up to $3.1 \times 10^{10} \mathrm{M}^{-1}$. The strong binding occurs through intercalation with the aromatic guests located inside the cage cavity between two naphthalene walls. Additionally, both guests and the free cage are redox-active. The guests can be switched into $\left(\mathbf{T T F} \rightarrow \mathbf{T} \mathbf{T F}^{2+}\right)$ and out $\left(\mathbf{M V}^{\mathbf{2}} \rightarrow \mathbf{M V}\right)$ of the cage with high selectivity by oxidation and reduction, respectively. The cage can be reversibly oxidized to its radical cation, which is stabilized by self-inclusion of the oxidized naphthalene. The oxidation of the cage can be applied for controlled guest release from the cage cavity, which paves the way for novel applications in redoxcontrolled guest release or in stimuli-responsive materials.

\section{ASSOCIATED CONTENT}

\section{Supporting Information}

The Supporting Information is available free of charge on the ACS Publications website at DOI:

Experimental and theoretical details, ${ }^{1} \mathrm{H}$ NMR and UV-vis spectra of the complexes, cyclic voltammetry experiments and singlecrystal X-ray data (pdf). Crystallographic data for $\mathbf{M V}^{2+} @ \mathbf{N C}$ (cif).

\section{AUTHOR INFORMATION}

\section{Corresponding Authors}

*c.schalley@,fu-berlin.de; jiangw@,sustech.edu.cn

\section{ORCID}

Fei Jia: 0000-0003-3212-692X

Hendrik V. Schröder: 0000-0002-6126-0055

Christoph Schalley: 0000-0002-8634-3578

Wei Jiang: 0000-0001-7683-5811

\section{Notes}

The authors declare no competing financial interests.

\section{ACKNOWLEDGMENTS}

This research was supported by the National Natural Science Foundation of China (grant nos. 21572097, 21822104, and 21801125), the Shenzhen Special Funds (KQJSCX20170728162528382, JCYJ20180504165810828) and the Shenzhen Nobel Prize Scientists Laboratory Project (C17213101). F. J. thanks the China Scholarship Council (CSC) for a $\mathrm{PhD}$ fellowship. We thank Henrik Hupatz for helpful discussions and help with UV/Vis experiments, Dr. Carlo Fasting for help with the purity analysis of naphthocage and Dr. Andreas Schäfer for help with EXSY measurements. Funding from the Deutsche Forschungsgemeinschaft (CRC 765 and core facility BioSupraMol) is gratefully acknowledged.

\section{REFERENCES}

(1) Guo, J.; Zhou, H.-X. Protein Allostery and Conformational Dynamics. Chem. Rev. 2016, 116, 6503.

(2) Koshland, D. E., Jr. Application of a Theory of Enzyme Specificity to Protein Synthesis. Proc. Natl. Acad. Sci. USA 1958, 44 98.

(3) (a) Callender, R.; Dyer, R. B. The Dynamical Nature of Enzymatic Catalysis. Acc. Chem. Res. 2015, 48, 407. (b) Bornscheuer, U. T. A Radical Change in Enzyme Catalysis. Nature, 2016, 540, 345. (c) Riccio, A.; Vitagliano, L.; di Prisco, G.; Zagari, A.; Mazzarella, L. The Crystal Structure of a Tetrameric Hemoglobin in a Partial
Hemichrome State. Proc. Natl. Acad. Sci. USA 2002, 99, 9801.

(4) (a) Richards, A. D.; Rodger, A. Synthetic Metallomolecules as Agents for the Control of DNA Structure. Chem. Soc. Rev. 2007, 36 , 471. (b) Almaqwashi, A. A.; Andersson, J.; Lincoln, P.; Rouzina, I.; Westerlund, F.; Williams, M. C. DNA Intercalation Optimized by Two-Step Molecular Lock Mechanism. Sci. Rep. 2016, 6, 37993.

(5) (a) Odell, B.; Reddington, M. V.; Slawin, A. M. Z.; Spencer, N.; Stoddart, J. F.; Williams, D. J. Cyclobis(paraquat-p-phenylene). A Tetracationic Multipurpose Receptor. Angew. Chem. Int. Ed. Engl. 1988, 27, 1547 .

(6) (a) Fahrenbach, A. C.; Bruns, C. J.; Cao, D.; Stoddart, J. F Ground-State Thermodynamics of Bistable Redox-Active DonorAcceptor Mechanically Interlocked Molecules. Acc. Chem. Res. 2012 45, 1581. (b) Fahrenbach, A. C.; Bruns, C. J.; Li, H.; Trabolsi, A.; Coskun, A.; Stoddart, J. F. Ground-State Kinetics of Bistable RedoxActive Donor-Acceptor Mechanically Interlocked Molecules. Acc. Chem. Res. 2014, 47, 482. (c) Pochorovski, I.; Diederich, F. Development of Redox-Switchable Resorcin[4]arene Cavitands. Acc. Chem. Res. 2014, 47, 2096. (d) Croué, V.; Goeb, S.; Sallé, M. Metaldriven Self-assembly: the Case of Redox-Active Discrete Architectures. Chem. Commun. 2015, 51, 7275. (e) Ogoshi, T.; Akutsu, T.; Shimada, Y.; Yamagishi, T. A. Redox-Responsive HostGuest System Using Redox-Active Pillar[5]arene Containing One Benzoquinone Unit. Chem. Commun. 2016, 52, 6479. (f) Yazaki, K.; Noda, S.; Tanaka, Y.; Sei, Y.; Akita, M.; Yoshizawa, M. An $\mathrm{M}_{2} \mathrm{~L}_{4}$ Molecular Capsule with a Redox Switchable Polyradical Shell. Angew. Chem. Int. Ed. 2016, 55, 15031. (g) Szalóki, G.; Croué, V.; Carré, V.; Aubriet, F.; Alévêque, O.; Levillain, E.; Allain, M.; Aragó, J.; Ortí, E.; Goeb, S.; Sallé, M. Controlling the Host-Guest Interaction Mode through a Redox Stimulus. Angew. Chem. Int. Ed. 2017, 129, 16272.

(7) (a) Jia, F.; He, Z.; Yang, L.-P.; Pan, Z.-S.; Yi, M.; Jiang, R.-W.; Jiang, W. Oxatub[4]arene: a Smart Macrocyclic Receptor with Multiple Interconvertible Cavities. Chem. Sci. 2015, 6, 6731. (b) Yang, L.-P.; Liu, W.-E.; Jiang, W. Naphthol-Based Macrocyclic Receptors. Tetrahedron Lett. 2016, 57, 3978. (c) Ke, H.; Yang, L.-P.; Xie, M.; Chen, Z.; Jiang, W. Shear-Induced Assembly of a Transient yet Highly Stretchable Hydrogel Based on Pseudopolyrotaxanes. Nat. Chem. 2019, 11, 470. (d) Jia, F.; Wang, H.-Y.; Li, D.-H.; Yang, L.-P. Jiang, W. Oxatub[4]arene: a Molecular "Transformer" Capable of Hosting a Wide Range of Organic Cations. Chem. Commun. 2016, 52, 5666.

(8) Jia, F.; Hupatz, H.; Yang, L.-P.; Schröder, H. V.; Li, D.-H.; Xin, S.; Lentz, D.; Witte, F.; Xie, X.; Paulus, B.; Schalley, C. A.; Jiang, W. Naphthocage: A Flexible yet Extremely Strong Binder for Singly Charged Organic Cations. J. Am. Chem. Soc. 2019, 141, 4468.

(9) Wang, Y.; Frasconi, M.; Stoddart, J. F. Introducing Stable Radicals into Molecular Machines. ACS Cent. Sci. 2017, 3, 927.

(10) Perrin, C. L.; Dwyer, T. J. Application of Two-Dimensional NMR to Kinetics of Chemical Exchange. Chem. Rev. 1990, 90, 935.

(11) Gan, Q.; Ferrand, Y.; Bao, C.; Kauffmann, B.; Grélard, A.; Jiang, H.; Huc, I. Helix-Rod Host-Guest Complexes with Shuttling Rates Much Faster than Disassembly. Science, 2011, 331, 1172.

(12) (a) Mirzoian, A.; Kaifer, A. E. Reactive Pseudorotaxanes: Inclusion Complexation of Reduced Viologens by the Hosts $\beta$-Cyclodextrin and Heptakis(2,6-di-O-methyl)- $\beta$-cyclodextrin. Chem. Eur. J. 1997, 3, 1052. (b) Simonsen, K. B.; Becher, J.; Thorup, N.; Cava, M. P. Synthesis and X-Ray Crystal Structure of the First Tetrathiafulvalene-Based Acceptor-Donor-Acceptor Sandwich. Chem. Commun. 1998, 8, 901.

(13) (a) Wudl, F.; Smith, G. M.; Hufnagel, E. J. Bis-1,3-dithiolium Chloride: An Unusually Stable Organic Radical Cation. J. Chem. Soc. $D$ 1970, 1453. (b) Jana, A.; Ishida, M.; Park, J. S.; Bähring, S.; Jeppesen, J. O.; Sessler, J. L. Tetrathiafulvalene- (TTF-) Derived Oligopyrrolic Macrocycles. Chem. Rev. 2017, 117, 2641. (c) Schröder, H. V.; Schalley, C. A. Tetrathiafulvalene - A Redoxswitchable Building Block to Control Motion in Mechanically Interlocked Molecules. Beilstein J. Org. Chem. 2018, 14, 2163. 
Table of Contents (TOC) Graphic

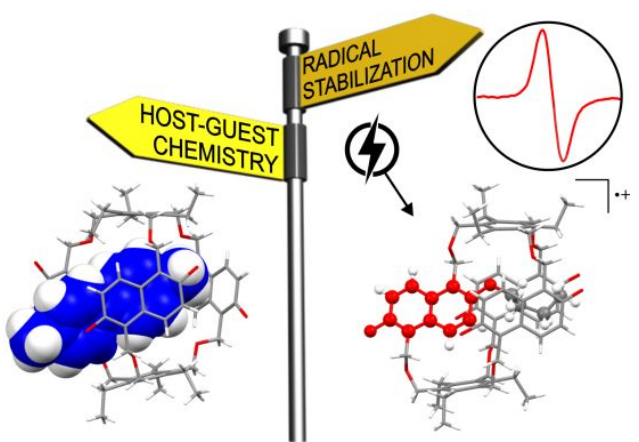

